Nghiem, L.D. ; Manis, A. ; Soldenhoff, K. ; Schäfer, A.I. (2004) Wastewater Treatment for Estrogenic Hormone Removal using NF/RO Membranes, Journal of Membrane Science, 242, 1-2, 37-45. doi:10.1016/j.memsci.2003.12.034

\section{ESTROGENIC HORMONE REMOVAL FROM WASTEWATER USING NF/RO MEMBRANES}

\author{
L.D. Nghiem ${ }^{1}$, A. Manis ${ }^{2}$, K. Soldenhoff ${ }^{2}$, A.I. Schäfer ${ }^{3 *}$
}

1 Civil and Environmental Engineering, University of New South Wales, Sydney, NSW 2052, Australia long.nghiem@yale.edu, ph: ++1-203-432 7195, fax: ++1-2034322895

Australian Nuclear Science \& Technology Organisation, Menai, NSW 2234, Australia

ama@ansto.gov.au, khs@ansto.gov.au, ph: ++619717 9214, fax: ++6197179260

Environmental Engineering, University of Wollongong, NSW 2522, Australia ( ${ }^{*}$ corresponding author)

A.Schaefer@uow.edu.au, Ph: ++ 61-2-4221 3385, fax: ++61-2-4221 3238

submitted to Journal of Membrane Science for the Edition in Honour of John Howell, Roger Ben-Aim and Tony Fane

\section{ABSTRACT}

This paper investigates the separation process of two estrogenic hormones, estrone and estradiol, using eight commercial NF and low pressure RO membranes. The results indicate that the separation mechanism of estrone and estradiol in membrane filtration processes is similar. While estrogenic hormone retention by porous membranes decreases with decreasing adsorption and the subsequent retention is relatively low, tigh $\mathrm{NF}$ and RO membranes can retain estrogenic hormones effectively. It appears that the presence of organic matter in solution can enhance retention due to the interaction of such substances with estrogenic hormones. The results also suggest that physicochemica interactions within the membrane can play an important role. There is no cross flow effe on retention, whereas an increase in transmembrane pressure may lead to a decrease in steroid hormones retention for some membranes.

Keywords: estrone, estradiol, endocrine disrupting chemicals (EDCs), nanofiltration, reserve osmosis, trace contaminants, membrane adsorption.

\section{INTRODUCTION}

The public health and environmental implications of the so called "Endocrine disrupting chemicals" (EDCs) have been the subject of many scientific investigations, media interest and policy attention over the last few years. Hundreds of compounds, whose abundance in the aquatic environment have been identified, are known to be EDCs. There has been a mounting number of evidence of endocrine disrupting effects on laboratory animals and wildlife exposed to those chemicals such as fish [1-3], birds [4, 5], amphibians [6], and panthers [7]. Several researchers also suggest a link between environmental EDCs exposure and deteriorating trends in human health including decreases in male sperm count, increases in testicular, prostate, ovarian and breast cancer, reproductive malfunctions $[8,9]$, amongst more com abnormalities [10]. Although, other researchers still caution about such a direct link and insist on more studies, it is now clear that fetus and new born babies are more vulnerable [10]. Public awareness and policy attention have recently spurred a number of studies investigating the fate and transport of EDCs in the environment, and particularly their removal in water and wastewater treatment processes.

Natural estrogenic hormones estradiol and estrone are by far the most endocrine disrupting chemicals. Their endocrine disrupting potency can be several thousands times disrupting che higher than that of other synthetic chemicals such as nonyl phenol (see Table 1). Concentration as low as $1 \mathrm{ng} / \mathrm{L}$ of estradiol can result in a distinctive endocrine disrupting effect in male trout [1]. Estradiol controls the development of the female sex characteristics in humans and together with the gestagens, control the reproductive process [11]. In fact, 17a-ethinylestradiol (a synthetic analogy of estradiol) is the main component of the contraceptive pill since it gives the same effect as this natural hormone. Under certain conditions, estradiol can be transformed into estrone.

Estrogenic hormones are continuously discharged by humans and animals into the environment either directly or after undergoing wastewater treatment processes, which are often not designed or capable of removing such contaminants. Removal efficiency of conventional wastewater treatment plants varies greatly [12]. Consequently, these hormones are ubiquitous in most fresh water bodies receiving effluent. They are frequently detected in North America, Europe, Japan, Brazil and China within the lower ng/L range [13-16]. A recent comprehensive study conducted by the US Geological Survey on fresh water resources across the US has revealed that the occurrence frequency of estradio respectively [15]. In particular, an estradiol concentration of $2.6 \mu \mathrm{g} / \mathrm{L}$ in the South Nevada Water System, which provides drinking water to the city, has been reported [17]. Estradio concentrations ranging form 6 to $66 \mathrm{ng} / \mathrm{L}$ have also been reported in groundwater (mantled karst aquifers in northwest Arkansas, USA) [18].

Although it is suggested that advanced technologies such as membrane filtration (reverse osmosis), advanced oxidation and activated carbon adsorption can effectively remove trace organic contaminants including estrogenic hormones [10], studies on the trace organic con performance of such technologies with regards to hormone removal are stll very limited. This can probably be attibuted to the fact that until recently, there have been few analytical methods capable of quantifying these compounds at the required trace levels. Such methods are tedious, skill-demanding and still mostly limited to reconnaissance missions. Further, it will not be feasible in the near future to monitor such contaminants on a regular basis, especially in complex matrices such as wastewaters.

Applications of nanofiltration (NF) and reverse osmosis (RO) in the water industry are growing. NF and RO processes are particularly effective to remove trace contaminants 
both inorganic (such as nitrate, arsenic and fluoride) [20,21] and organic (such as pesticides and other synthetic organics chemicals) [22-24]. Removal of emerging wastewater pollutants namely pharmaceutical active compounds [25] and steroid hormones [26] has recently been studied at their environmental concentration (in the order of $\mathrm{ng} / \mathrm{L})$. However, such studies are still scarce and there is a need to further expand our understanding of the retention mechanisms of such low concentration contaminants in $\mathrm{NF}$ and RO membrane processes.

In previous works, we have studied the retention mechanisms of estrone by NF/RO membranes using bench scale equipment (stirred cells). The results indicate that estrone can adsorb onto the membranes to some extent, depending on membrane type and the solution chemistry [27]. Both sieving and adsorptive mechanisms are instrumental in maintaining high retention in nanofiltration membranes that otherwise exhibit relatively low ion retention [26].

In this study, using cross flow filtration equipment and eight different commercial NF/RO membranes, we reconfirm such findings and further elucidate other factors governing the retention of estrogenic hormones. Estrone and estradiol retentions were compared. The influence of other bulk organic matter in the solution on estrogenic hormone retention was examined. Finally, the study considers the effects of different operating variables namely cross flow velocity and transmembrane pressure on retention.

\section{MATERIALS AND METHODS}

\subsection{Membranes}

Eight commercial membranes were selected for this study, namely TFC-S, TFC-ULP, TFC-SR1, and TFC-SR2 supplied by Koch Membrane Systems (San Diego, USA) and X20, ACM-4, TS-80, and XN-40 supplied by Trisep Corporation (Goleta, USA). It has been shown in our previous work that all membranes are negatively charged near $\mathrm{pH}$ neutral [26]. Hydrophobicity of the membranes is also described elsewhere [26]

\subsection{Filtration System and Protocol}

The cross flow filtration system includes a SEPA® cross-flow cell (Osmonics), a feed pump, a recirculation pump (Micropump), and a digital flowmeter. A picture of the system is shown in Fig. 1. The effective membrane surface area is $138.7 \mathrm{~cm}^{2}(146 \times 95 \mathrm{~mm})$ and the channel height is $0.86 \mathrm{~mm}$. Prior to the experiment with the cross flow system, the membranes were gently washed using $\mathrm{DI}$ water to remove the protective coating and a new membrane was used for each experiment. The membranes were compacted for at least 1 hour using DI water at 10 bar. Pure water flux was then determined at the end of the compaction process. The feed reservoir was then emptied and the system was drained out to avoid dilution. The feed reservoir was then refilled with the test solution. The applied pressure was 10 bar and both permeate and retentate were recycled to the feed reservoir, unless otherwise stated. Permeate and feed samples were collected for analysis at specified intervals.

Feed solution was prepared by spiking estrone or estradiol into a solution containing background electrolyte $\left(20 \mathrm{mM}\right.$ of $\mathrm{NaCl}$ and $1 \mathrm{mM}$ of $\left.\mathrm{NaHCO}_{3}\right)$, synthetic surface water or secondary effluent solution to a concentration of $100 \mathrm{ng} / \mathrm{L}$. This presents a typical concentration of natural hormones often encountered in domestic wastewaters while still ensuring analytical accuracy. A feed volume of $3.5 \mathrm{~L}$ was used for each experiment. Retention is defined as: $R=100 \times\left(1-\frac{C_{P}}{C_{F}}\right)$, where $C_{p}$ and $C_{F}$ are permeate and feed concentrations (ng/L), respectively.

\subsection{Solution Chemistry and Chemicals}

All chemicals were of analytical grade. Radiolabelled estrone-2,4,6,7- ${ }^{3} \mathrm{H}(\mathrm{N})$ and estradiol$2,4-{ }^{3} \mathrm{H}(\mathrm{N})$ (92\% purity) were purchased from Sigma Aldrich (Saint Louis, Missouri, USA). Secondary effluent was obtained from Brendale wastewater treatment plant in Queensland, Australia. Previous analysis showed that it contains about $10 \mathrm{mg} / \mathrm{L}$ total organic carbon (TOC), $50 \mathrm{mg} / \mathrm{L}$ of sodium and $10 \mathrm{mg} / \mathrm{L}$ of calcium [28]. Natural organic matter (NOM) was concentrated from Mooney-Mooney dam. Surface water using $10 \mathrm{mg} / \mathrm{L}$ of NOM in background electrolyte was used in this project. TOC was analysed by using a Shimadzu TOC-5000 instrument. The instrument was set on high sensitive catalyst and NPOC (non-purgeable organic carbon) analysis.

\subsection{Natural Hormone Characteristics and Analysis}

Estrone and estradiol have a very low solubility in water (see Table 2). Their $\mathrm{K}_{\text {ow }}$ values suggest their hydrophobic nature and moderate to high binding to colloids and macromolecules in water. Laboratory studies indicates that estrone and estradiol can adsorb moderately onto sediment [29]. The acid dissociation constant, pKa, of estrone is 10.4 [26]. Given the similarity in structure between the two compounds, it is expected that pKa of estradiol is also 10.4. Functional groups of estrone can facilitate the formation of hydrogen bonding between the molecule and the membrane surface. Theoretically, estrone can be either a proton-donor or a proton-acceptor species, while estradiol can only act as a proton-donor. Molecular structures of estrone and estradiol are shown in Fig. 2.

Estrone and estradiol were analysed using a Packard Instruments scintillation counter. This technique offered excellent accuracy with a detection limit of less than $0.1 \mathrm{ng} / \mathrm{L}$.

\section{RESULTS AND DISCUSSION}

\subsection{Retention of estrogenic hormone estrone}

Retention of estrone by 8 different NF/RO membranes in the cross-flow system in a clean matrix solution (background electrolyte in DI water) is shown in Fig. 3. Although both sieving and adsorptive effects are instrumental in maintaining retention, for tight NF and RO membranes, size exclusion becomes the overriding mechanism and adsorption mostly occurs on the membrane surface [30]. In such circumstances, adsorption does not contribute to the overall retention of the membrane and this can be observed for the TFCS, TFC-ULP, X-20, TS-80 and ACM-4 membranes.

Estrone retentions of the TFC-SR2, TFC-SR1, and XN-40 membranes decrease until equilibrium between estrone and the membrane has been established. Subsequent retention when stabilized is lower than the initial value. As reported previously, these membranes exhibit generally low ions retention. Sodium chloride retention of TFC-SR2, TFC-SR1, and XN-40 membranes are in the range between 2 to $17 \%, 24$ to $32 \%$ and 21 to $34 \%$, respectively [26]. The transport mechanism of estrone across these membranes can be characterized as convection dominated and both sieving and adsorptive mechanisms are effective in retaining estrone [27]. However, the membrane adsorptive capacity becomes exhausted over time as solution is filtered through the membrane, only sieving mechanism plays a role in long term retention.

This results in clear break-through curves similar to that which is in other adsorption processes such as activated carbon (see Fig. 4). For TFC-SR1 and XN-40 membranes, at the break-through point, the permeate concentration is far less than the initial feed concentration because of the sieving effect and depletion of estrone due to adsorption. Nishiyama et al., investigated the adsorptive interaction between estradiol and porous hollow fiber membranes (average pore size of $0.4 \mathrm{\mu m}$ ) and reported a similar break 
through phenomenon [31]. However, at the point of break through, permeate concentration is equal to the feed concentration. This also shows that there is no sieving effect as the membrane pore size is much larger than the estradiol molecules.

\subsection{Comparison of estrone and estradiol retention}

Retention of estrone and estradiol in a clean matrix solution using TFC-S and TFC-SR2 membranes is shown in Figure 5. Although there are small differences between estrone and estradiol retentions, such differences are well within the experimental errors reported (approximately 3\%) in our earlier publication [26]. Estrone has a 17-keto group, whereas estradiol has a 17-hydroxyl group. Other than that, they have a similar molecular structure (see Fig. 2). The results indicate that the 3-oxygen atoms of the first ring of estrone and estradiol may predominantly participate in hydrogen bonding with the membrane polymer. This is consistent with the result reported by Le Questel et al., [32] in their study of the hydrogen bonding formation between progesterone to its human receptor. Data reported in their study indicate that the 3-oxygen atom of progesterone is the predominant hydrogen bonding acceptor.

\subsection{Effects of bulk organic matter}

Organic compounds occur naturally and are ubiquitous in any aquatic environment where they often determine the surface properties of any solids in contact with water. Organic matter found in water spans a wide spectrum, their molecular weight ranging from severa hundred thousands to less than a hundred Daltons (grams per mol). While natural wate contains compounds mostly on the lower end of this spectrum, secondary effluent contains even lower molecular weight organics as they have been broken down during biological treatment processes. Although bulk organics are not considered harmful to human health they are relevant the precursor for the formation of carcinogenic trihalomethanes (THMs) and other disinfection by-products after disinfection. Further, as contaminants like estrone can bind to organic matter, their presence can enhance retention and generally determine the fate of compounds. Finally, some fraction of organic matter may compete with estrone for adsorptive sites. Consequently, this competition can also affect retention where adsorption is a dominating factor.

To study the effects of organic matter on estrone retention, experiments were conducted in three different matrix solutions: pure background electrolyte matrix, secondary effluent, and synthetic surface water (natural organic matter concentrated from Mooney Mooney Dam in background electrolyte). lonic strengths of the clean matrix and the synthetic Dum in background electrol surface water were prepared to be approximately that of secondary effluent. Likewise, the organic content of synthetic surface water was selected to be identical to that of secondary effluent $(\mathrm{TOC}=10 \mathrm{mg} / \mathrm{L})$

Estrone retentions in the different matrix solutions by X-20, TFC-S and TFC-SR2 membranes are shown in Fig. 6A, B, and C, respectively, whereas TOC retention in secondary effluent is shown in Fig. 7. It appears that estrone retention is enhanced by the presence of organic matter. Furthermore, this enhancement seems to be stronger for than in secondary effluent (containing organic matter of smaller molecular weights). Large molecules can be retained more effectively, hence, exert a stronger influence on estrone retention. However, this phenomenon is not observed for TFC-SR2 membranes, possibly due to its larger pore size. Reported results are consistent with an earlier study by Agbekodo et al., [33] who investigated the influence of natural organic matter concentration on atrazine and simazine retention by the NF-70 membrane. An increase in atrazine and simazine retention as a function of organic matter concentration in the feed solution was reported.

\subsection{Comparison of cross-flow and dead-end filtration}

Although the application of dead end filtration configuration using NF or RO membranes is not common as it is prone to fouling, the simplicity of dead end filtration equipment such as stirred cells makes them a preferable testing tool for many membrane researchers. In contrast to cross-flow filtration, recovery in dead-end mode can be very high, which results contrast to cross-flow filtration, recovery in dead-end mode can be very high, which results
in a significant concentration factor and can represent the recovery effect on concentration inside real life modules very well. Fig. 8 shows the comparison between cross flow and dead end filtration. Experiments using a stirred cell were conducted in an earlier study [30] where a series of fresh estrone solutions $(100 \mathrm{ng} / \mathrm{L})$ were consecutively filtered through a single TFC-S membrane sample to examine if membrane saturation could be achieved.

While retentions are in agreement for a permeate volume of up to $200 \mathrm{~mL}$, as the permeate volume increases retention obtained from the stirred cell starts deviating from that of the cross flow cell. In dead end filtration, a volume of permeate is drawn from the feed solution without any replenishment, which results in a continuous increase in feed concentration in the cell. As fresh estrone solutions are repeatedly introduced to the stirred cell, estrone retention increases in each dead end filtration cycle due to the difference in concentration at the end and the beginning of the next one. At the end of each filtration cycle estrone is accumulated on the membrane surface, which results in a greater the transport of estrone that diffusion rate of aromatic compounds such as bisphenol A and 2-chlorophenol in dense membrane can be relatively fast if the compounds are readily to partition into the membrane polymer [34]. The results indicate that dead end filtration test may underestimate the long term retention of the membrane. The effect of operating variables such as cross flow velocity and transmembrane pressure are consequently investigated in the following sections.

\subsection{Effects of operating variables}

Understanding the impact of operating variables on retention of trace contaminants is of paramount importance from design as well as operational points of view. The influence of cross-flow velocity and operating pressure on estrone retention was examined in this study. The XN-40 membrane was selected as it exhibits medium range estrone retention. solution in background electrolyte matrix for 5 hours at 10 bar. Cross-flow velocity was then varied from $0.073 \mathrm{~m} / \mathrm{s}$ to $0.24 \mathrm{~m} / \mathrm{s}$. A fresh solution was used to examine the operating pressure effects on retention. After equilibrating the membrane with the same procedure, the pressure was varied from 10 to 25 bar. Three samples at each cross-flow velocity or operating pressure were taken for analysis at an interval of 15 minutes.

Estrone retention as a function of cross-flow velocity is shown in Fig. 9. An increase in cross-flow velocity can reduce the polarization concentration at the membrane-bulk solution interface. The effect could lead to an increase in retention. However, no cross-flow onto the membrane surface, the estrone concentration within the membrane can be higher than that of the polarization layer. Therefore, the polarization concentration effect appears in this case negligible.

The results are different for a variation in operating pressure. Fig. 10 shows that estrone retention decreases by $15 \%$ as the pressure increases from 10 to 25 bar. In general, solute retention increases with pressure up to an asymptotic value. However, for organic solute retention increases with pressure up to an asymptotic value. However, for organic solutes that have strong interaction with membrane polymers, retention may decrease with
pressure [35]. It has been reported that retentions of chlorophenol [36], chloroform [37] pressure [35]. It has been reported that retentions of chlorophenol [36], chloroform [37],
and nonyl phenol [38] decrease as pressure increases. Interestingly, these contaminants were similarly reported to be able to adsorb to the membrane. While the results are 
consistent, a plausible explanation is to date not available and our hypothesis is that pressure influences the membrane-solute interactions.

Solute membrane interactions can be friction (governed by hydrodynamic conditions) and diffusion (governed by chemical concentration gradient). The average pore diameter of the $\mathrm{XN}-40$ membrane was determined to be $0.7 \mathrm{~nm}$ followed a method described elsewhere [39], which is in the same order of magnitude as the molecular size of estrone, such interactions can be critical. An increase in pressure results in an increase in permeate flux; and hence the drag force desorption of estrone can be enhanced or time for adsorption reduced due to the lowers residence time in the membrane which may contribute to the drop in retention. In addition, an increase in pressure will also lead to an increase in permeate recovery, which further reduces the retention.

\section{CONCLUSIONS}

The separation process of two estrogenic hormones estrone and estradiol was investigated using eight commercially available NF and low pressure RO membranes. Results reported here indicate the similarity between estrone and estradiol with regards to separation in membrane filtration. Depending on the pore size, adsorption can affect the 作 can effectively retain estrogenic hormones, retention of porous membranes (TFC-SR2, TFC-SR1 and XN-40) decreases as adsorption decreases illustrating a breakthrough curve, and the subsequent long-term retention of these three membranes is relatively low. The presence of organic matter appears to enhance hormone retention. This enhancement is apparently stronger in natural water, in which organic matter generally has larger molecular weight, than that in secondary effluent. Cross flow is more effective than the dead end configuration, probably due to lower adsorption. There is no cross flow effect on retention, whereas an increase in operation pressure results in a decrease in hormone retention. Both of these are most likely linked to the membrane - solute interactions observed.

\section{ACKNOWLEDGEMENT}

The Australian Institute of Nuclear Science and Engineering and Australian Nuclear Science \& Technology Organisation are thanked for project funding under grant no R-02157S. We acknowledge Koch Membrane Systems (San Diego, USA) and Trisep Corporation (Goleta, USA) for providing membrane samples, and Brendale City Council for providing secondary effluent samples.

\section{REFERENCE}

[1] Purdom, C.E., P.A. Hardiman, V.J. Bye, N.C. Eno, C.R. Tyler, and J.P. Sumpter, Estrogenic effects of effluents from sewage treatment works. Journal of Chemistry and Ecology, (1994). 8 : p. 275-285.

[2] Harries, J.E., D.A. Sheahan, S. Jobling, P. Matthienssen, P. Neall, J.P. Sumpter, T. Tylor, and $\mathrm{N}$. Zaman, Estrogenic activities at five UK rivers detected by measurement of vitellogenesis in caged male trout. Journal of Environmental Toxicology and Chemistry, (1997). 16: p. 534-542.

[3] Lye, C.M., C.L.J. Frid, M.E. Gill, and D. McCormick, Abnormalties in the Reproductive Health of Flounder Platichthys flesus Exposed to Effluent from a Sewage Treatment Works. Marine Pollution Bulletin, (1997). 34(1): p. 34-41.

[4] Tanabe, S., Contamination and toxic effects of persistent endocrine disrupters in marine mammals and birds. Marine Pollution Bulletin, (2002). 45(1-12): p. 69-77.
[5] Ottinger, M.A., M. Abdelnabi, M. Quinn, N. Golden, J. Wu, and N. Thompson, Reproductive consequences of EDCs in birds: What do laboratory effects mean in field species? Neurotoxicology and Teratology, (2002). 24(1): p. 17-28.

[6] Carey, C. and C.J. Bryant, Possible interrelations among Environmental toxicants, Amphibian development, and decline of Amphibian population. Environmental Health Perspectives, (1995). 103(4): p. 13-18.

[7] Facemire, C.F., T.S. Gross, and L.T. Guillette, Reproductive impairment in the Florida panther: Nature or Nurture. Environmental Health Perspectives, (1995). 103(4): p. 79-86.

[8] Michael, J., Are problem with male reproductive health cause by endocrine disruption? Occupational \& Medicine Education, (2001). 58: p. 281-288

[9] Hess, R.A., D. Bunick, K.-H. Lee, J. Barh, J.A. Taylor, K.S. Korach, and D.B. Lubahn, A role for oestrogens in the male reproductive system. Letters to nature, (1997). 390: p. 509-512.

10] Colborn, T., D. Dumanoski, and J.P. Myers, Our stolen future. 2 ed. (1997), London, UK: Abacus.

[11] Turan, A., Excretion of Natural and Synthetic Estrogens and their Metabolites: Occurrence and Behaviour in water. (1995), Berlin: German Environmental Agency.

[12] Johnson, A.C. and J.P. Sumpter, Removal of Endocrine-Disrupting Chemicals in activated sludge treatment works. Environmental Science \& Technology, (2001). 35: p. 4697-4703.

[13] Ternes, T.A., M. Stumpf, J. Mueller, K. Haberer, R.-D. Wilken, and M. Servos, Behavior and occurrence of estrogens in municipal sewage treatment plants - I. Investigations in Germany, Canada and Brazil. The Science of the Total Environment, (1999). 225: p. 81-90.

[14] Shen, J.H., B. Gutendorf, H.H. Vahl, L. Shen, and J. Westendorf, Toxicological profile of pollutants in surface water from an area in Taihu Lake, Yangtze Delta. Toxicology, (2001). 166(1-2): p. 71-78.

[15] Kolpin, D.W., E.T. Furlong, M.T. Meyer, E.M. Thurman, S.D. Zaugg, L.B. Barber, and H.T. Buxton, Pharmaceuticals, Hormones, and Other Organic Wastewater Contaminants in U.S. Streams, 1999-2000: A National Reconnaissance. Environmental Science \& Technology, (2002). 36(6): p. 1202-1221.

[16] Tabata, A., S. Kashiwada, Y. Ohnishi, H. Ishikawa, N. Miyamoto, M. Itoh, and Y. Magara, Estrogenic influences of estradiol-17ß, p-nonylphenol and bis-phenol-A on Japanese Medaka (Oryzias latipes) at detected environmental concentrations. Journal of Water Science \& Technology, (2001). 43(2): p. 109-116.

[17] Roefer, P., S. Snyder, D.J. Zegers, and J.L. Fronk, Endocrine-disrupting chemicals in a source water. J AWWA, (2000). 92(8): p. 52-58.

[18] Peterson, E.W., R.K. Davis, and H.A. Orndorff, 17ק-Estradiol as an indicator of animal waste contamination in mantled karst aquifers. Journal of Environmental Quality, (2001). 29: p. 826834.

[19] Ternes, T.A., M. Meisenheimer, D. McDowell, F. Sacher, H.-J. Brauch, B. Haist-Gulde, G. Preuss, U. Wilme, and N. Zulei-Seibert, Removal of Pharmaceuticals during Drinking Water

[20] Choi, S., Z. Yun, S. Hong, and K. Ahn, The effect of co-existing ions and surface charateristics of nanomembranes on the removal of nitrate and fluoride. Desalination, (2000). 133: p. 53-64.

[21] Waypa, J.J., M. Elimelech, and J.G. Hering, Arsenic removal by RO and NF membranes. Journal AWWA, (1997). Oct '97: p. 102-114.

[22] Duranceau, S.J., J.S. Taylor, and L.A. Mulford, SOC removal in a membrane softening process. Journal AWWA, (1992). Jan: p. 68-78.

[23] Van der Bruggen, B., J. Schaep, W. Maes, D. Wilms, and C. Vandecasteele, Nanofiltration as a treatment method for the removal of pesticides from ground waters. Desalination, (1998). 117(1-3): p. 139-147.

[24] Van der Bruggen, B. and C. Vandecasteele, Removal of pollutants from surface water and groundwater by nanofiltration: overview of possible applications in the drinking water industry. Environmental Pollution, (2003). 122(3): p. 435-445.

[25] Heberer, T., D. Feldmann, K. Reddersen, H. Altmann, and T. Zimmermann, Production of drinking water from highly contaminanted surface waters: removal of organic, inorganic, and microbial contaminants applying mobile membrane filtration units. acta Hydrochimica Hydrobiologica, (2002). 30(1): p. 24-33 
Nghiem, L.D. ; Manis, A. ; Soldenhoff, K. ; Schäfer, A.I. (2004) Wastewater Treatment for Estrogenic Hormone Removal using NF/RO Membranes, Journal of Membrane Science, 242, 1-2, 37-45. doi:10.1016/j.memsci.2003.12.034

[26] Schäfer, A.I., D.L. Nghiem, and T.D. Waite, Removal of the Natural Hormone Estrone from Aqueous Solutions Using Nanofiltration and Reverse Osmosis. Environmental Science \& Aqueche

[27] Nghiem, D.L. and A.I. Schäfer, Adsorption and Transport of Trace Contaminant Estrone in NF/RO Membranes. Environmental Engineering Science, (2002). 19(6): p. 441-451.

[28] Schäfer, A.I., D.L. Nghiem, and D. Waite. Removal of natural hormones estrone and estradio in secondary effluent and surface water using NF/RO membranes. in Membrane technology for Wastewater Reclamation and Reuse. (2001). Tel-Aviv, Israel: IWA.

[29] Lai, K.M., K.L. Johnson, M.D. Scrimshaw, and J.N. Lester, Binding of water-borne steroid estrogens to solid phases in river and esturies systems. Environmental Science \& Technology, (2000). 34: p. 3490-3494

[30] Nghiem, L.D., A.I. Schäfer, and T.D. Waite, Adsorptive interactions between membranes and trace contaminants. Desalination, (2002). 147(1-3): p. 269-274.

[31] Nishiyama, S., A. Goto, K. Saito, K. Sugita, M. Tamada, T. Sugo, T. Funami, Y. Goda, and S. Fujimoto, Concentration of $17 \beta$-Estradiol Using an Immunoaffinity Porous Hollow-Fiber Membrane. Analytical Chemistry, (2002). 74: p. 4933-4936.

[32] Le Questel, J., G. Boquet, M. Berthelot, and C. Laurence, Hydrogen Bonding of Progesterone: a Combined Theoretical, Spectroscopic, Thermodynamic, and Crystallographic Database Study. Journal of Physical Chemistry, (2000). 104: p. 11816-11823.

[33] Agbekodo, K.M., B. Legube, and S. Dard, Atrazine and simazine removal mechanisms by nanofiltration: influence of natural organic matter concentration. Water Research, (1996). 30(11): p. 2535-2542.

[34] Gro $\beta$, A. and A. Heinzt, Diffusion coefficients of aromatics in nonporous PEBA membranes. Journal of Membrane Science, (2000). 168(1-2): p. 233-242.

[35] Ho, W.S.W. and K.K. Sirkar, Membrane Handbook. (1992), New York: van Nostrand Reinhold.

[36] Sourirajan, S. and T. Matsuura, Physicochemical criteria for reverse osmosis separations, in Reverse osmosis and synthetic membranes, S. Sourirajan, Editor. (1977), National Research Council Canada: Ottawa.

[37] Ducom, G. and C. Cabassud, Interests and limitations of nanofiltration for the removal of volatile organic compounds in drinking water production. Desalination, (1999). 124(1-3): $p$. 115-123.

[38] Gallenkemper, M., T. Wintgens, and T. Melin. Nanofiltration of endocrine disrupting compounds. in Membranes in Drinking and Industrial water Production. (2002). Mulheim an der Ruhr: IWW.

[39] Nghiem, D.L., A.I. Schäfer, and M. Elimelech, Removal of Natural Hormones by Nanofiltration Membranes: Measurement, Modeling, and Mechanisms. Environmental Science \& Technology, (Submitted, Aug 2003).

[40] Pelissero, C., G. Flouriot, J.L. Foucher, B. Bennetau, J. Dunogues, F. Le Gac, and J.P. Sumpter, Vitellogenin synthesis in cultured hepatocytes; an in vitro test for the estrogenic Sumpter, Vitellogenin synthesis in cultured hepatocytes; an in vitro test for the estrogenic
potency of chemicals. The Journal of Steroid Biochemistry and Molecular Biology, (1993). potency of chemicas p. 263-272.

[41] Jobling, S. and J.P. Sumpter, Detergent components in sewage effluent are weakly oestrogenic to fish: An in vitro study using rainbow trout (Oncorhynchus mykiss) hepatocytes. Oestrogenic to fish: An in vitro study using
Figure 1: Cross flow filtration equipment.

Figure 2: Molecular structure of estradiol (left) and estrone (right).

Figure 3: Retention of estrone by $8 \mathrm{NF} / \mathrm{RO}$ membranes (10 bar, $1 \mathrm{mM} \mathrm{NaHCO} 3,20 \mathrm{mM}$ $\mathrm{NaCl}$, cross flow velocity of $0.073 \mathrm{~m} / \mathrm{s}, \mathrm{pH} \sim 8$ ).

Figure 4: Estrone concentration in permeate by TFC-SR1, TFC-SR2, and XN-40 membranes as a function of time (10 bar, $1 \mathrm{mM} \mathrm{NaHCO}, 20 \mathrm{mM} \mathrm{NaCl}$, cross flow velocity of $0.073 \mathrm{~m} / \mathrm{s}, \mathrm{pH} \sim 8$ ).

Figure 5: Estrone versus estradiol retention (10 bar, $1 \mathrm{mM} \mathrm{NaHCO}_{3}, 20 \mathrm{mM} \mathrm{NaCl}$, cross flow velocity $0.073 \mathrm{~m} / \mathrm{s}, \mathrm{pH} \sim 8$ ).

Figure 6: Estrone retention in different matrix solution by X-20 (A), TFC-S (B) and TFC SR2 (C) (10 bar, cross flow velocity of $0.073 \mathrm{~m} / \mathrm{s}, \mathrm{pH} \sim 8$, surface water and secondary effluent solutions contain $10 \mathrm{mg} / \mathrm{L}$ organic matters).

Figure 7: TOC retention in secondary effluent (10 bar, cross flow velocity of $0.073 \mathrm{~m} / \mathrm{s}, \mathrm{pH}$ 8)

Figure 8: Estrone retention by TFC-S membrane during dead end and cross flow filtration (10 bar, $1 \mathrm{mM} \mathrm{NaHCO} 3,20 \mathrm{mM} \mathrm{NaCl}$, cross flow velocity of $0.073 \mathrm{~m} / \mathrm{s}, \mathrm{pH} \sim 8$ ).

Figure 9: Estrone retention as a function of cross flow velocity (XN-40 membrane, $1 \mathrm{mM}$ $\mathrm{NaHCO}_{3}, 20 \mathrm{mM} \mathrm{NaCl}, \mathrm{pH} \sim 8$ ).

Figure 10: Estrone retention as a function of operating pressure (XN-40 membrane, $1 \mathrm{mM}$ $\mathrm{NaHCO}_{3}, 20 \mathrm{mM} \mathrm{NaCl}$, cross flow velocity of $0.073 \mathrm{~m} / \mathrm{s}, \mathrm{pH} \sim 8$ ). 
Nghiem, L.D. ; Manis, A. ; Soldenhoff, K. ; Schäfer, A.I. (2004) Wastewater Treatment for Estrogenic Hormone Removal using NF/RO Membranes, Journal of Membrane Science, 242, 1-2, 37-45. doi:10.1016/j.memsci.2003.12.034

Figure 1

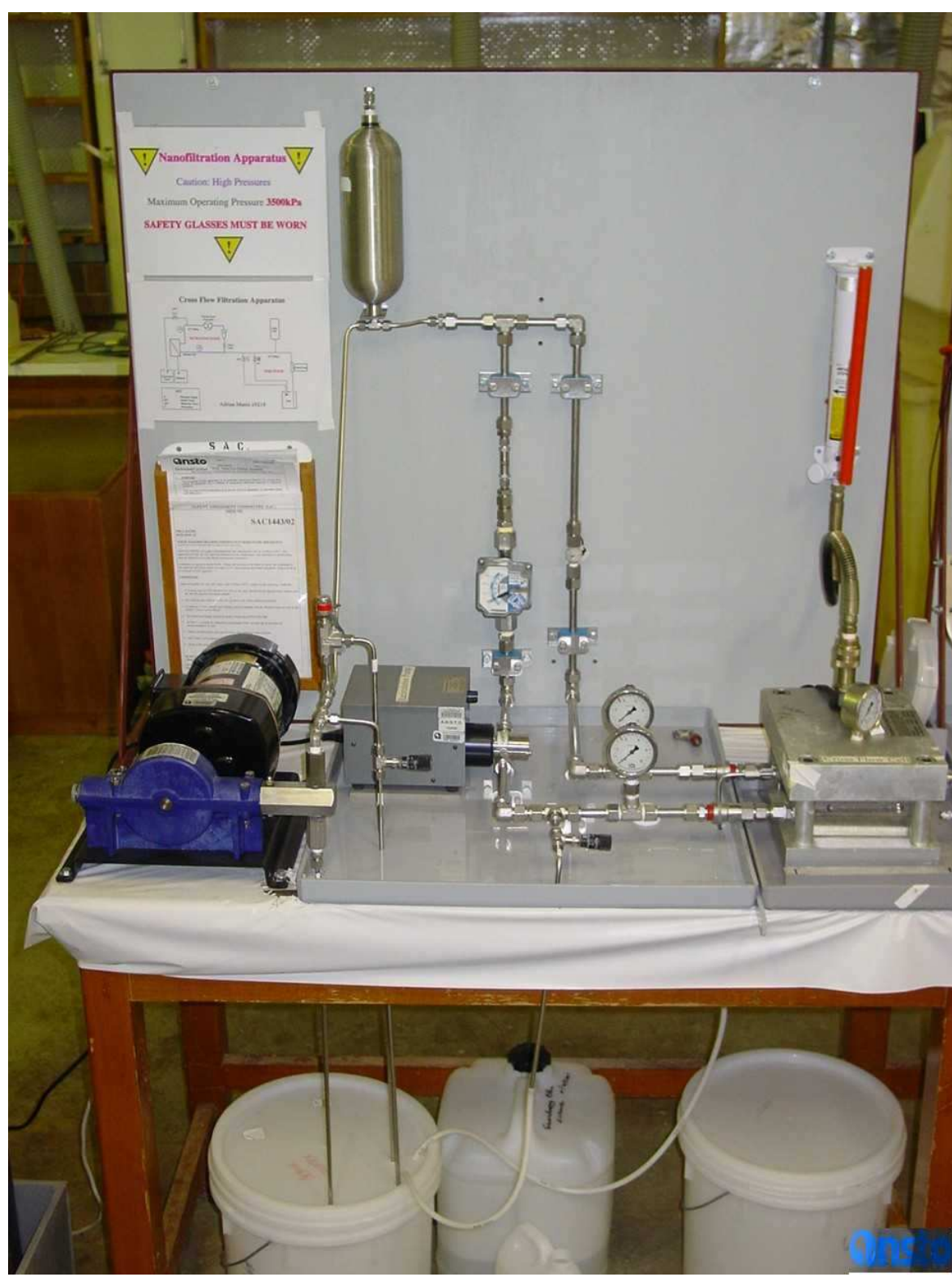

Figure 2

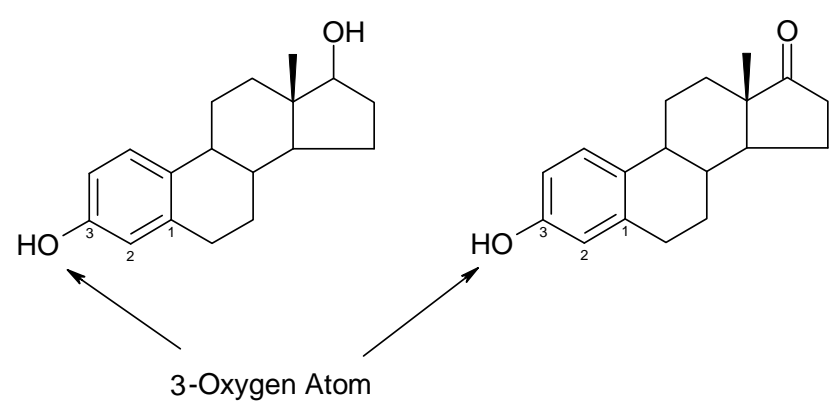

Figure 3
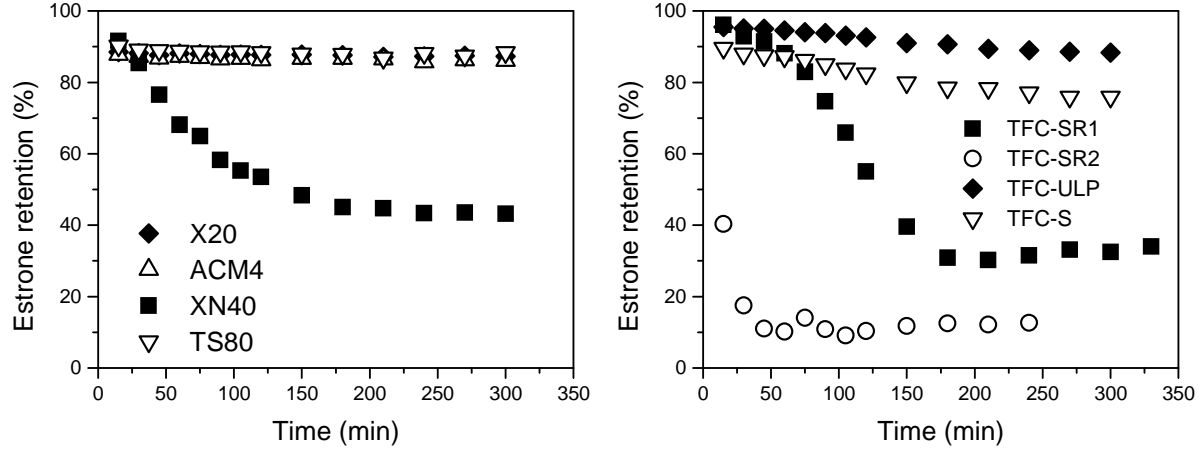
Nghiem, L.D. ; Manis, A. ; Soldenhoff, K. ; Schäfer, A.I. (2004) Wastewater Treatment for Estrogenic Hormone Removal using NF/RO Membranes, Journal of Membrane Science, 242, 1-2, 37-45. doi:10.1016/j.memsci.2003.12.034

Figure 4

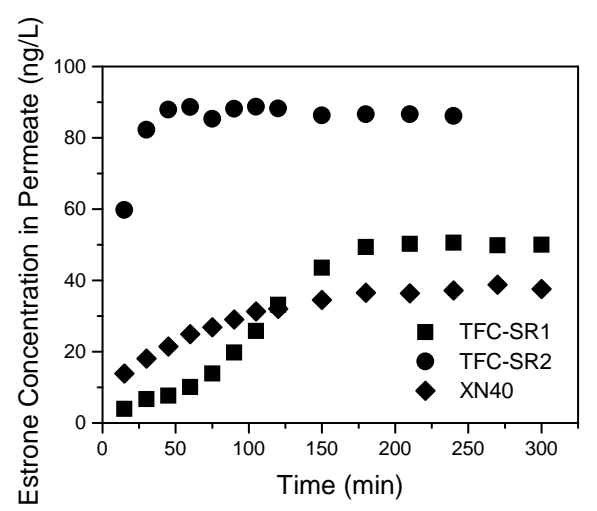

Figure 5

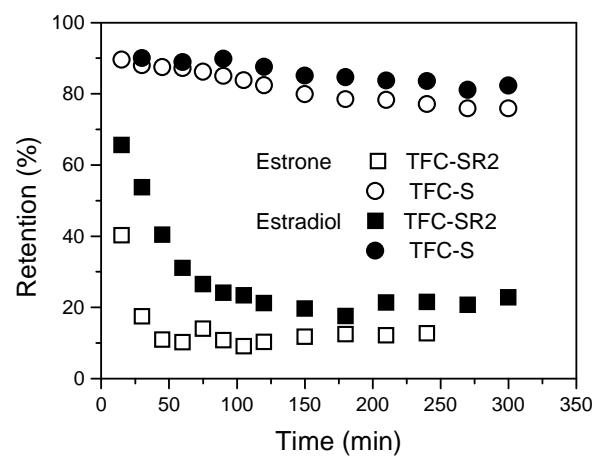

Figure 6
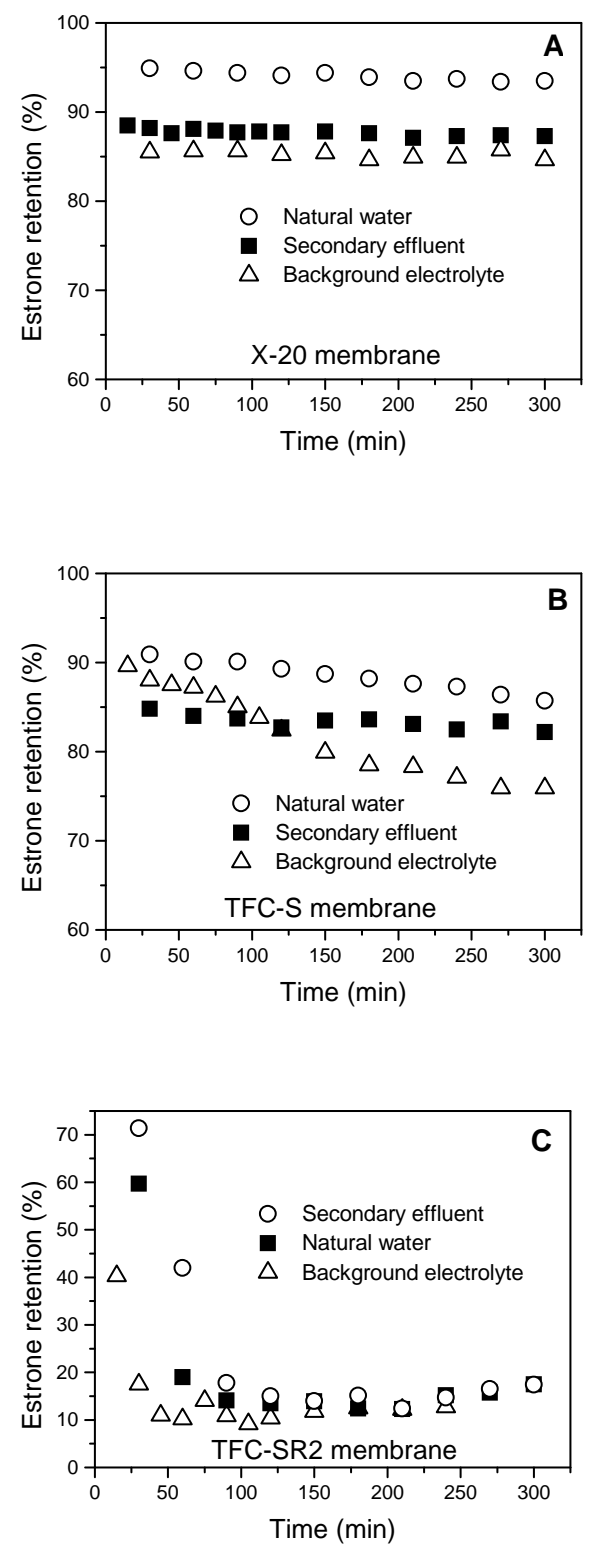
Nghiem, L.D. ; Manis, A. ; Soldenhoff, K. ; Schäfer, A.I. (2004) Wastewater Treatment for Estrogenic Hormone Removal using NF/RO Membranes, Journal of Membrane Science, 242, 1-2, 37-45. doi:10.1016/j.memsci.2003.12.034

Figure 7

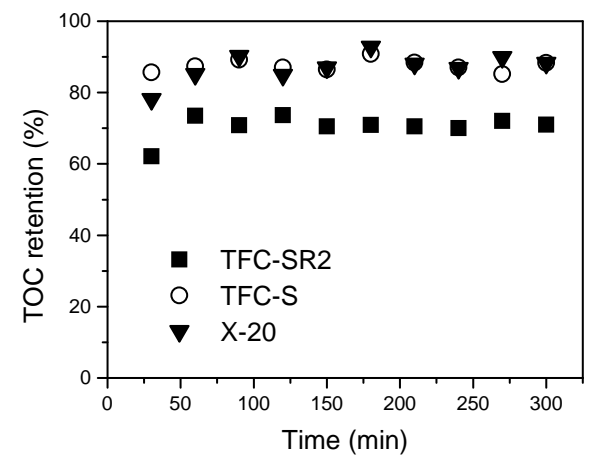

Figure 8

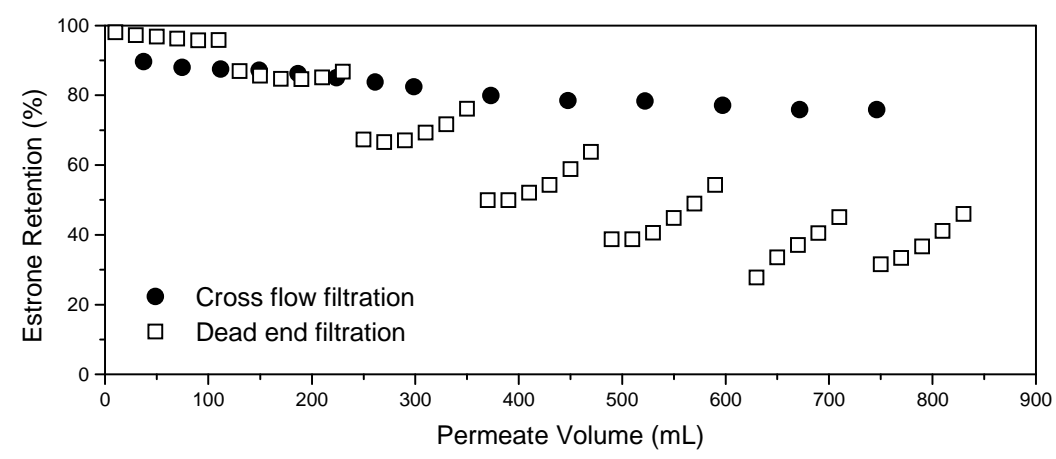

Figure 9

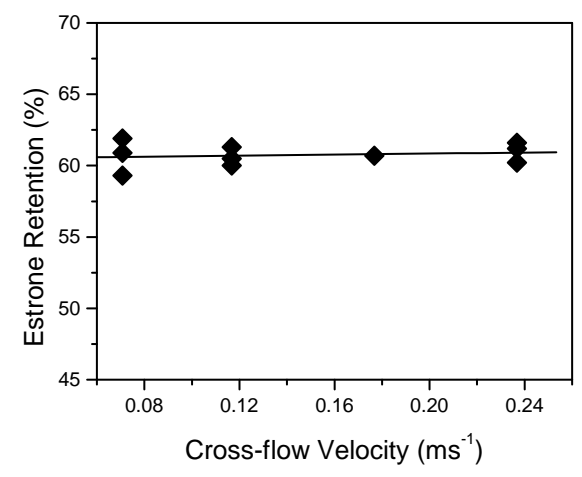

Figure 10

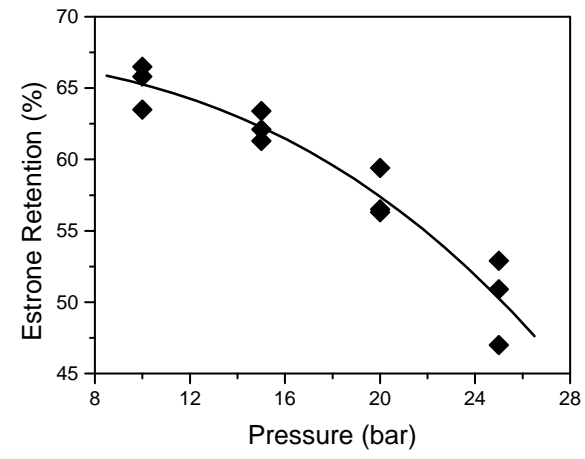


Nghiem, L.D. ; Manis, A. ; Soldenhoff, K. ; Schäfer, A.I. (2004) Wastewater Treatment for Estrogenic Hormone Removal using NF/RO Membranes, Journal of Membrane Science, 242, 1-2, 37-45. doi:10.1016/j.memsci.2003.12.034

Table 1: Examples of endocrine disrupting potency in relation to estrone and estradiol.

\begin{tabular}{|l|c|c|}
\hline Substance & Relative potency & Reference \\
\hline Estradiol & 1 & \\
\hline Estrone & 1 \\
\hline Progesterone & $2 \times 10^{-2}$ & {$[40]$} \\
\hline Testostrone & $1 \times 10^{-2}$ & \\
\hline Phytoestrogenes & $<1 \times 10^{-3}$ & \\
\hline 4-Nonyl-phenol & $9 \times 10^{-6}$ & \\
\hline
\end{tabular}

Table 2: Physicochemical properties of estrogenic hormones

\begin{tabular}{|c|c|c|c|c|}
\hline Hormones & $\begin{array}{l}\text { Molecular } \\
\text { weight }\end{array}$ & $\begin{array}{l}\text { Water solubility } \\
\text { at } 20^{\circ} \mathrm{C}^{\mathrm{a}}\end{array}$ & $\mathrm{pKa}^{\mathrm{b}}$ & $\log \mathrm{K}_{\text {ow }}{ }^{\mathrm{a}}$ \\
\hline Estradiol & $272.4 \mathrm{~g} / \mathrm{mol}$ & $13 \mathrm{mg} / \mathrm{L}$ & 10.4 & 3.94 \\
\hline Estrone & $270.4 \mathrm{~g} / \mathrm{mol}$ & $13 \mathrm{mg} / \mathrm{L}$ & 10.4 & 3.43 \\
\hline
\end{tabular}

${ }^{a}[29]$

${ }^{b}[26]$ 